\title{
Comparison of anti amoebic activity of stereoisomeric diamino and monoamino pregnene alkaloids and their $\mathrm{N}$-methylated analogs
}

\author{
RAJ M VAID $^{\mathrm{a}, *}$ and K K BHUTANI ${ }^{\mathrm{b}}$ \\ ${ }^{a}$ Organic Chemistry Division, Regional Research Laboratory, Indian Institute of Integrative Medicine (IIIM), \\ Canal Road, Jammu 180 001, India \\ bNational Institute of Pharmaceutical Education and Research, (NIPER), \\ Sector 67, SAS Nagar, (Mohali) 160 062, India \\ e-mail: RajMVaid@yahoo.com; director@niper.ac.in
}

MS received 25 February 2012; accepted 25 May 2012

\begin{abstract}
The steroidal alkaloid 3 $\beta, 20 \alpha$-diamino-pregn-5-ene (kurchamine) obtained from the stem bark of Holarrhena antidysenterica is reported to have appreciable amoebicidal activity. Its three stereoisomers namely

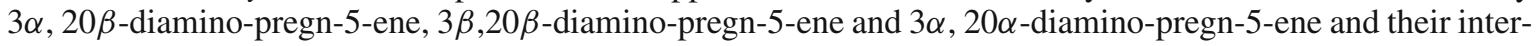
mediate stereoisomeric monoamino pregnene alkaloids namely $3 \beta$-amino-pregn-5-ene-20-one, $3 \alpha$-aminopregn-5-ene-20-one, $20 \alpha$-amino-pregn-5-ene-3 $\beta$-ol, $20 \beta$-amino-pregn-5-ene-3 $\beta$-ol were synthesized. The natural stereoisomer and synthesized diamino and monoamino stereoisomers were N-methylated and all the compounds were evaluated for amoebicidal activity comparison. The natural stereoisomer $3 \beta, 20 \alpha$-diamino-pregn5-ene (kurchamine) was found to be superior than other stereoisomers and N-methylation was found to have insignificant effect on amoebicidal activity of stereoisomers.
\end{abstract}

Keywords. Holarrhena antidysenterica; amoebiasis; kurchamine; conessine; diamino pregnene; monoamino pregnene; stereoisomers.

\section{Introduction}

Stem bark of Holarrhena antidysenterica (Kurchi) has been traditionally used for the treatment of amoebiasis. $^{1,2}$ A number of steroidal alkaloids belonging to conenine and pregnene series have been reported from this plant. ${ }^{3}$ As already reported ${ }^{4,5}$ comparative evalution of antiamoebic activity of both series of alkaloids, pregnene alkaloid $3 \beta, 20 \alpha$-diamino-pregn-5-ene (kurchamine) was found to be most active even better than the conenine principal alkaloid conessine. This prompted us to evaluate the other known stereoisomers of kurchamine as well as their intermediate stereoisomeric monoamino pregnenes with the aim to find a better amoebicidal compound as compared to kurchamine and to know the quantum of change in the amoebicidal behaviour of intermediate mono amino pregnenes as these are transformed into diamino pregnene stereoisomers. It was also planned to $\mathrm{N}$-methylate, the natural and synthesized mono and diamino stereoisomers so as to enhance their amoebicidal activity as was observed in coenine alkaloids of this plant.

*For correspondence

\section{Experimental}

\subsection{Materials and methods}

Melting points were determined in open capillaries and are uncorrected. IR were recorded for $\mathrm{KBr}$ discs on Perkin-Elmer instrument. ${ }^{1} \mathrm{H}$ NMR spectra were recorded on Varian $60 \mathrm{MHz}$ instrument in $\mathrm{CDCl}_{3}$ with TMS as an internal standard and chemical shifts are given in parts per million (ó scale). Column chromatography was carried out in basic $\mathrm{Al}_{2} \mathrm{O}_{3}$. TLC was run on silica gel coated glass plates. In BenzeneEthylacetate- $\mathrm{Et}_{2} \mathrm{NH}$ (6:3:1) and spots were developed by dragendorffs reagent. Authentic samples of 16-DPA, conessine, conarrhimine, $3 \beta 20 \alpha$ - diamino-pregn-5-ene (kurchamine) were obtained inhouse.

2.1a $3 \alpha$-Amino -pregn-5-ene -20-one (1): It was obtained as crystalline solid. Yield: $-60.0 \%$, m.p. $130-132^{\circ} \mathrm{C}$ (lit ${ }^{9}$ m.p. $135-136^{\circ} \mathrm{C}$ ). ${ }^{1} \mathrm{H}$ NMR $\left(60 \mathrm{MHz}, \mathrm{CDCl}_{3}\right)$ : ó 0.75 (s,3H), 1.09 (s, 3H), 2.05 (s, $3 \mathrm{H})$ and 5.32 (brs, $1 \mathrm{H})$.

2.1b 3 $\beta$-Amino -pregn-5-ene -20-one (2): It was obtained as $\mathrm{HCl}$ salt. Yield: $-45.0 \%$, m.p. $>300^{\circ} \mathrm{C}$, IR : 3250,2920,1715, and $810 \mathrm{~cm}^{-1} ;{ }^{1} \mathrm{H}$ NMR 
(60 MHz, $\mathrm{CDCl}_{3}$ ): ó 0.68 (s, 3H), 0.90 (s, 3H), 2.08 (s, $3 \mathrm{H})$ and $5.32(\mathrm{brs}, 1 \mathrm{H})$.

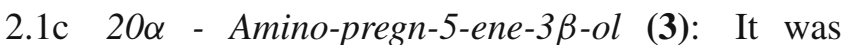
obtained as crystalline solid. Yield: $-2.6 \%$, m.p. 164 $66^{\circ} \mathrm{C}$ (lit ${ }^{9}$ m.p. $\left.177^{\circ} \mathrm{C}\right) .{ }^{1} \mathrm{H}$ NMR $\left(60 \mathrm{MHz}, \mathrm{CDCl}_{3}\right)$ : ó $0.68(\mathrm{~s}, 3 \mathrm{H}), 0.98$ (s, 3H), 1.16 (d, 3H, J $6 \mathrm{~Hz})$ and 5.32 (brs, 1H).

2.1d $20 \beta$-Amino-pregene-5-ene-3 $\beta$-ol (4): It was obtained as crystalline solid. Yield: $-18.35 \%$, m.p. 230 $35^{\circ} \mathrm{C}$ (lit ${ }^{9}$ m.p. $218-20^{\circ} \mathrm{C}$ ), IR :3450,2935,1465 and $1050 \mathrm{~cm}^{-1}$; ${ }^{1} \mathrm{H}$ NMR (60 MHz, $\mathrm{CDCl}_{3}$ ): ó 0.68 (s, 3H), 1.01(s, 3H), 1.03 (d,3H, J 7Hz) and 5.32 (brs, 1H).

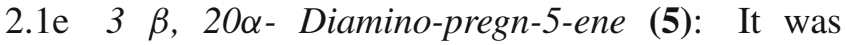
obtained as crystalline solid. Yield: $-0.12 \%$, m.p. $145-47^{\circ} \mathrm{C}$ (lit ${ }^{9}$ m.p. $148^{\circ} \mathrm{C}$ ). IR:3400,2900,1410 and $1320 \mathrm{~cm}^{-1} ;{ }^{1} \mathrm{H}$ NMR $\left(60 \mathrm{MHz}, \mathrm{CDCl}_{3}\right){ }^{1} \mathrm{H}$ NMR $\left(60 \mathrm{MHz} \mathrm{CDCl}_{3}\right)$ : ó 0.68 (s,3H), 1.00 (s, 3H), 1.10 (d, $3 \mathrm{H}, \mathrm{J} 6 \mathrm{~Hz}) .2 .0$ (s, 4H, $\mathrm{D}_{2} \mathrm{O}-$ exchangeable) and 5.32 (brs, $1 \mathrm{H})$.

2.1f $3 \alpha, 20 \alpha$-Diamino-pregn-5-ene (6): It was obtained as a solid. Yield: $-68 \%$, m.p. $148-150^{\circ} \mathrm{C}$ (lit ${ }^{9}$ m.p. $149-151^{\circ} \mathrm{C}$ ), IR: $3400,2900,1550,1390$ and $780 \mathrm{~cm}^{-1} ;{ }^{1} \mathrm{H}$ NMR $\left(60 \mathrm{MHz}, \mathrm{CDCl}_{3}\right)$ : ó $0.68(\mathrm{~s}, 3 \mathrm{H})$, $0.97(\mathrm{~s}, 3 \mathrm{H}), 1.16(\mathrm{~d}, 3 \mathrm{H}, \mathrm{J} 6 \mathrm{~Hz}), 1.86(\mathrm{~m}, 4 \mathrm{H}), 3.16$ (brs, $1 \mathrm{H})$ and 5.32 (brs, $1 \mathrm{H})$.

$2.1 \mathrm{~g} 3 \beta, 20 \beta$-Diamino-pregn-5-ene (7): It was obtained as solid. Yield: $-54.7 \%$, m.p. $145-46^{\circ} \mathrm{C}\left(\right.$ lit $^{9}$

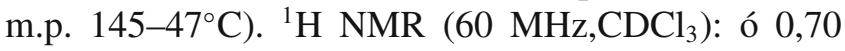
$(\mathrm{s}, 3 \mathrm{H}), 0.98(\mathrm{~s}, 3 \mathrm{H}), 1.05(\mathrm{~d}, 3 \mathrm{H}, \mathrm{J} 6.5 \mathrm{~Hz})$ and 5.32 (brs, $1 \mathrm{H})$.

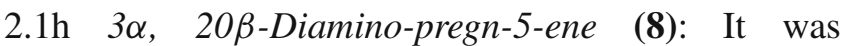
obtained as crystalline solid. Yield: $-86.15 \%$, m.p. 154 $56^{\circ} \mathrm{C}$ (lit ${ }^{9}$ m.p. $\left.158^{\circ} \mathrm{C}\right) .{ }^{1} \mathrm{H}$ NMR $\left(60 \mathrm{MHz}, \mathrm{CDCl}_{3}\right): \delta$ $0.68(\mathrm{~s}, 3 \mathrm{H}), 1.03(\mathrm{~s}, 6 \mathrm{H})$ and $5.32(\mathrm{brs}, 1 \mathrm{H})$.

\section{Results and discussion}

Except for few alkaloids such as $3 \beta, 20 \alpha$-diamino-pregn5-ene (kurchamine) (5) ${ }^{6,7}$ and $3 \beta, 20 \alpha$ - bisdimethylaminopregn-5-ene (kurchessine) $(11)^{8}$ other stereoisomeric diamino and monoamino pregnene alkaloids are not reported from this plant (H. antidysenterica). To carryout the study, the stereoisomeric di and mono amino pregnene alkaloids were synthesized starting from 16-DPA (Dehydropregnenolone acetate) following the literature methodology ${ }^{9}$ with few modifications wherever necessitated. ${ }^{10}$ The compounds synthesized were $3 \alpha$ - aminopregn-5-ene-20-one (1), $3 \beta$-amino-pregn-5-ene-20-one
(2), $20 \alpha$-amino -pregn-5-ene-3 $\beta$-ol (3), 20 $\beta$-amino -pregn-5-ene-3 $\beta$-ol (4), $3 \alpha, 20 \alpha$-diamino- pregn-5-ene (6), $3 \beta, 20 \beta$-diamino-pregn-5-ene (7) and $3 \alpha, 20 \beta$ diamino-pregn-5-ene $(\mathbf{8})$. The synthesized compounds were confirmed by comparison of spectral data with the literature values. ${ }^{9}$ To complete the series stereoisomer $3 \beta$, 20 $\alpha$-diamino-pregn-5-ene (kurchamine) (5) was isolated from the methanolic extract of powdered stem bark of kurchi ( $H$. antidysenterica) plant by column chromatography in $\mathrm{Al}_{2} \mathrm{O}_{3}$ (basic) by gradient elution using pet.ether (60-80)- ethylacetate-methanol. ${ }^{10}$ All the synthesized compounds and natural stereoisomer (5) were subjected to amoebicidal activity tests in vitro. ${ }^{11}$ The results obtained in terms of MIC are shown in table 1. A glance at the results shows that that among the diamino stereoisomers $3 \beta, 20 \alpha$-diamino-pregn-5ene (5) the natural stereoisomer (kurchamine) with $3 \beta$, $20 \alpha$ disposition of amino grs is most active there by corroborating the earlier findings $s^{4,5}$ followed by $3 \alpha, 20 \alpha$ - diamino-pregn-5-ene (6) whose activity was found to be half of natural stereoisomer (5) and equal to conessine (16), the stereoisomer $3 \beta, 20 \beta$-diamino-pregn-5ene (7) had activity half of (6) and the stereoisomer $3 \alpha, 20 \beta$-diamino-pregn-5-ene (8) was found to be four times less active as compared to the stereoisomer (7). The results also show that the introduction of one amino gr at $\mathrm{C}-20$ position in $\alpha$ orientation in pregnene nucleus induces appreciable activity in $20 \alpha$-amino-pregn-5-ene (3) and is comparable to $3 \alpha 20 \alpha$-diamino isomer (6) and conessine (16) but half as active as (5). The other mono amino stereoisomer (4) with C- 20 amino gr in $\beta$ orientation was found to have four times less activity

Table 1. Amoebicidal activity results of mono and diamino pregnene stereoisomers, conarrhimine and their $\mathrm{N}$ methylated analogs.

\begin{tabular}{lllll}
\hline Compound & $\mathrm{R} 1$ & $\mathrm{R} 2$ & $\mathrm{R} 3$ & $\mathrm{MIC}(\mu \mathrm{g} / \mathrm{ml})$ \\
\hline $\mathbf{1}$ & $\alpha-\mathrm{NH}_{2}$ & - & $=\mathrm{O}$ & $\mathrm{NA}$ \\
$\mathbf{2}$ & $\beta-\mathrm{NH}_{2}$ & - & $=\mathrm{O}$ & $\mathrm{NA}$ \\
$\mathbf{3}$ & $\beta-\mathrm{OH}$ & $\mathrm{H}$ & $\alpha-\mathrm{NH}_{2}$ & 62 \\
$\mathbf{4}$ & $\beta-\mathrm{OH}$ & $\beta-\mathrm{NH}_{2}$ & $\mathrm{H}$ & 250 \\
$\mathbf{5}$ & $\beta-\mathrm{NH}_{2}$ & $\mathrm{H}$ & $\alpha-\mathrm{NH}_{2}$ & 31.75 \\
$\mathbf{6}$ & $\alpha-\mathrm{NH}_{2}$ & $\mathrm{H}$ & $\alpha-\mathrm{NH}_{2}$ & 62.50 \\
$\mathbf{7}$ & $\beta-\mathrm{NH}_{2}$ & $\beta-\mathrm{NH}_{2}$ & $\mathrm{H}$ & 125 \\
$\mathbf{8}$ & $\alpha-\mathrm{NH}_{2}$ & $\beta-\mathrm{NH}_{2}$ & $\mathrm{H}$ & 500 \\
$\mathbf{9}$ & $\beta-\mathrm{OH}$ & $\mathrm{H}$ & $\alpha-\mathrm{NMe}_{2}$ & $\mathrm{NA}$ \\
$\mathbf{1 0}$ & $\beta-\mathrm{OH}$ & $\beta-\mathrm{NMe}_{2}$ & $\mathrm{H}$ & $\mathrm{NA}$ \\
$\mathbf{1 1}$ & $\beta-\mathrm{NMe}_{2}$ & $\mathrm{H}$ & $\alpha-\mathrm{NMe}_{2}$ & 125 \\
$\mathbf{1 2}$ & $\alpha-\mathrm{NMe}_{2}$ & $\mathrm{H}$ & $\alpha-\mathrm{NMe}_{2}$ & $\mathrm{NA}$ \\
$\mathbf{1 3}$ & $\beta-\mathrm{NMe}_{2}$ & $\beta-\mathrm{NMe}_{2}$ & $\mathrm{H}$ & 500 \\
$\mathbf{1 4}$ & $\alpha-\mathrm{NMe}_{2}$ & $\beta-\mathrm{NMe}_{2}$ & $\mathrm{H}$ & $\mathrm{NA}$ \\
$\mathbf{1 5}$ & $\mathrm{H}$ & $\mathrm{H}$ & $\mathrm{H}$ & $\mathrm{NA}$ \\
$\mathbf{1 6}$ & $\mathrm{Me}$ & $\mathrm{Me}$ & $\mathrm{Me}$ & 62.50 \\
\hline
\end{tabular}

NA -No activity was observed up to $1000(\mu \mathrm{g} / \mathrm{ml})$ 
as compared to the $20 \alpha$-amino isomer (3). The C-3 amino $\alpha$ and $\beta$ stereoisomers ( $\mathbf{1}$ and $\mathbf{2}$ ) were found to be inactive at the tested concentrations.

Keeping in view of the conenine series of alkaloids of this plant where amoebicidal activity increases as the degree of methylation of nitrogens at C-3 and C-20 increases as this was observed in conarrhimine (15) the parent base not active but fully N-methylated parent base conessine (16) has appreciable activity. The synthesized pregnene stereoisomers $(\mathbf{3}, \mathbf{4}, \mathbf{6}-\mathbf{8})$ and natural stereoisomer (kurchamine) (5) were $\mathrm{N}$ methylated with $\mathrm{HCHO}-\mathrm{HCOOH}{ }^{10}$ thus yielding $20 \alpha$-dimethylamino -pregn-5-ene $\quad-3 \beta$-ol (9), $20 \quad \beta$-dimethylamino -pregn-5-ene -3 $\beta$-ol (10), $3 \beta, 20 \alpha$-bis dimethylaminopregn-5-ene (11)), $3 \alpha, 20 \alpha$-bisdimethylamino-pregn5-ene (12), 3 $\beta, 20 \beta$-bis dimethylamino- pregn-5-ene (13), $3 \alpha, 20 \beta$-bisdimethyiamino-pregn-5-ene (14) and their amoebicidal activity was evaluated in vitro. The results (table 1) indicate that N-methylation of stereoisomers has resulted in appreciable fall in activity instead of enhancement of activity as was observed in conenine series. The amoebicidal activity results indicate that the stereoisomer (5) has superior activity as compared to other stereoisomers. The better activity of (5) appears to be due to the presence of two amino groups at less hindered

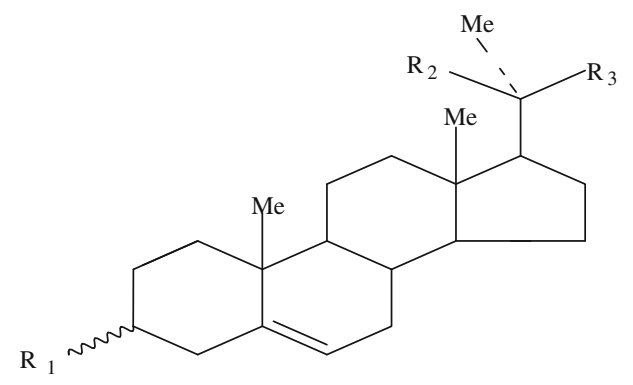

1 - 14

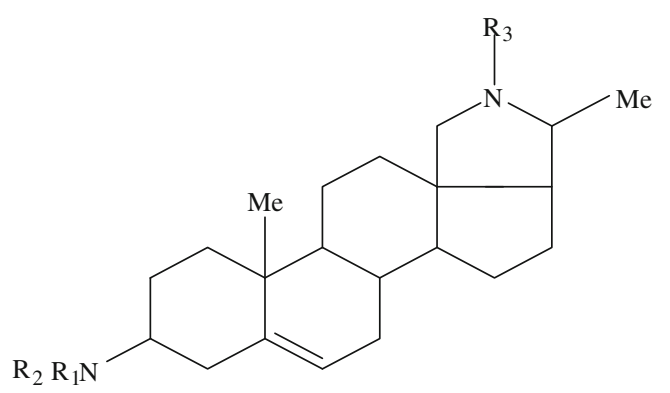

$15 \mathrm{R}_{1} \mathrm{R}_{2} \mathrm{R}_{3}=\mathrm{H}$

$16 \mathrm{R}_{1}, \mathrm{R}_{2} \mathrm{R}_{3}=\mathrm{Me}$
C-3 $\beta$ and C-20 $\alpha$ sites which enables better interaction and annihilation of amoebae and makes the natural stereoisomer superior to others. To comment on the exact mechanism involved is beyond the scope of this work.

\section{Conclusion}

The stereoisomers of kurchamine were found to have amoebicidal activity but were not comparable to natural stereoisomer and the order of activity was found to be $3 \beta, 20 \alpha$-diamino-pregn-5-ene (5) > 3 $\alpha, 20 \alpha$-diaminopregn-5-ene $(6)>3 \beta, 20 \beta$-diamino-pregn-5-ene (7) $>3 \alpha, 20 \beta$-diamino-pregn-5-ene (8). Among the mono amines $20 \alpha$-amino isomer (3) was found to have appreciable activity comparable to $3 \alpha, 20 \alpha$ - diamino stereoisomer (6) whereas $20 \beta$ mono amino isomer (4) was found to have four times less activity as compared to $20 \alpha$ amino isomer (3). N-methylation of all the synthesized stereoisomers and kurchamine resulted in remarkable fall in amoebicidal activity of respective compounds.

\section{Acknowledgements}

The authors are thankful to Dr. G L Sharma and Ravinder Kour of Organic Chemistry Division, Regional Research Laboratory, Jammu (RRL) for biological testing of the compounds. RMV is thankful to the Council of Scientific and Industrial Research (CSIR) for the award of Junior Research Fellowship (JRF).

\section{References}

1. Sastri B N, Chief Ed 1959 The wealth of India, raw materials (New Delhi: Council of Scientific and Industrial Research) V 103

2. Koul M K and Atal C K 1983 J. Ethnopharmaco. 8349

3. Chauha Y R (ed) 1982 Bibliography of Holarrhena antidysenterica, Med. Aromat. Plants Abstr. 4351

4. Bhutani K K 1984 Proceedings of National Symposium on Applied Biotechnology of Medicinal, Aromatic and Timber Yielding Plants [NSASMATP] (Calcutta University) 387

5. Bhutani K K, Sharma G L and Atal C K 1985 Indian J. Pharmocol. 17(Suppl.I) 37

6. Truong-Ho M, Khuong-Huu Q and Goutarel R 1963 Bull. Soc. Chim. Fr. 594

7. Tschesche R and Otto P 1962 Chem. Ber. 951144

8. Chatterjee A, Dass B, Dutta C P and Mukerjee K S 1965 Tetrahedron Lett. 67

9. Goutarel R, Mahler H R, Green G, Khuong-Huu Q, Cave A, Conreur M C, Jarreau F X and Hannart J 1967 Bull. Soc. Chim. Fr. 4575

10. Vaid R M 1988 Modulations of Kurchi alkaloids, Ph.D Thesis (Jammu: University of Jammu)

11. Bhutani K K, Kumar V, Kour R and Sarin A N 1987 Indian Drugs $\mathbf{2 4} 508$ 